\title{
Preterm arteries in childhood: dimensions, intima-media thickness, and elasticity of the aorta, coronaries, and carotids in 6-y-old children born extremely preterm
}

\author{
Lilly-Ann Mohlkert ${ }^{1,2}$, Jenny Hallberg ${ }^{2,3}$, Olof Broberg ${ }^{4}$, Monica Hellström ${ }^{5}$, Cecilia Pegelow Halvorsen ${ }^{2,6}$, Gunnar Sjöberg ${ }^{7}$, \\ Anna-Karin Edstedt Bonamy, ${ }^{7,8}$, Petru Liuba ${ }^{4}$, Vineta Fellman ${ }^{9,10}$, Magnus Domellöf5 and Mikael Norman ${ }^{1,11}$
}

BACKGROUND: Preterm birth increases risk for adult cardiovascular disease. We hypothesized that arteries in 6-y-old children born preterm are narrower, with thicker intima-media and stiffer than in peers born at term.

METHODS: Children born extremely preterm (EXP, $n=176$, birthweights: $348-1,161 \mathrm{~g})$ and at term (CTRL, $n=174$, birthweights: 2,430-4,315 g) were included. Using ultrasonography, we determined diameters of the coronaries (CA), common carotid arteries (CCA) and aorta, the carotid intima media thickness (CIMT), and the stiffness index of the CCA and aorta.

RESULTS: Arteries were 5-10\% narrower in EXP than in CTRL $(P<0.005)$ but after adjustment for body surface area, diameter differences diminished or disappeared. EXP-children born small for gestational age exhibited similar arterial dimensions as those born appropriate for date. The cIMT was 0.38 (SD = 0.04) $\mathrm{mm}$ and did not differ between groups. Carotid but not aortic stiffness was lower in EXP than in CTRL.

CONCLUSION: In 6-y-old children born extremely preterm, conduit arteries are of similar or smaller size than in controls born at term, and they have no signs of accelerated intima media thickening or arterial stiffening. While these findings are reassuring for these children and their families, the causal pathways from preterm birth to adult cardiovascular disease remain unknown.

\footnotetext{
A
} lthough preterm birth still is a major cause of death on a global level, survival after preterm birth has increased significantly in many countries (1). As a result, there are approximately 20 million children (0-18 y) born preterm in Europe and North America, and the population of young adults born preterm is growing. This development is associated with previously unknown adult health issues: several studies link preterm birth to an increased risk for morbidities in adulthood, such as later hypertension $(2,3)$, diabetes $(4,5)$, stroke (6-8), accelerated cardiac aging (9), and even early death from cardiovascular disease (CVD) (10).

Studies of cardiovascular structure and function in children born preterm may help clarifying how birth-related events interact with and predict childhood and adult outcomes. Immediately after preterm birth, growth of retinal microvessels (11) and of large arteries such as the carotids and aorta (12) slow down compared with fetal development. Long-term follow-up data suggest that this birth-related decrease in vascular growth velocity after preterm birth may be a persisting and generalized phenomenon (13-17). Some reports but not all $(14,18-21)$ also suggest that, besides arterial narrowing, accelerated intima-media thickening $(17,22)$ and early loss of arterial elasticity $(23,24)$ may be involved in the causal pathway from preterm birth to CVD.

Among infants born extremely preterm, survival is nowadays the most probable outcome (1). Given a dose-response relationship between each incremental decrease in gestational age and increasing cardiovascular risk in adult life $(2,10)$, we hypothesized that children born extremely preterm exhibit adverse arterial growth (diameter) and premature vascular aging (intima-media-thickening and wall-stiffening) compared with age- and sex-matched control children born at term. To test these hypotheses, we performed a comprehensive 6.5 -y follow-up of a population-based cohort of infants surviving extremely preterm birth.

\section{METHODS}

Participants

The Extremely Preterm Infants in Sweden Study (EXPRESS) included all pregnant women residing in Sweden and delivering infants before 27 wk of gestation, from 1 April 2004 to 31 March 2007. Detailed characteristics of this prospectively collected population-based cohort, as

\footnotetext{
'Department of Clinical Science, Intervention and Technology, Karolinska Institutet, Stockholm, Sweden; ${ }^{2}$ Sachs' Children and Youth Hospital, Södersjukhuset, Stockholm, Sweden; ${ }^{3}$ nstitute of Environmental Medicine, Karolinska Institutet, Stockholm, Sweden; ${ }^{4}$ Department of Clinical Sciences, Division of Pediatric Cardiology, Lund University, and Pediatric Heart Center, Skåne University Hospital, Lund, Sweden; ${ }^{5}$ Department of Clinical Sciences, Pediatrics, Umeå University, Umeå, Sweden; ${ }^{6}$ Department of Clinical Science and Education, Karolinska Institutet, Stockholm, Sweden; ${ }^{7}$ Department of Women's and Children's Health, Karolinska Institutet, Stockholm, Sweden; ${ }^{8} \mathrm{Clinical}$ Epidemiology

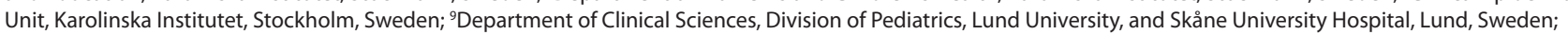
${ }^{10} \mathrm{C}$ ildren's Hospital, University of Helsinki, Helsinki, Finland; " ${ }^{1}$ Department of Neonatal Medicine, Karolinska University Hospital, Stockholm, Sweden. Correspondence: Lilly-Ann Mohlkert (lilly-ann.mohlkert@ki.se)

Received 21 March 2016; accepted 13 August 2016; advance online publication 21 December 2016. doi:10.1038/pr.2016.212
} 


\section{Articles Mohlertet tal.}

well as data on survival, neonatal morbidity, and neurodevelopmental outcomes at 30 mo of age have been reported $(1,25,26)$.

All EXPRESS-children were invited to a comprehensive follow-up study at $6.5 \mathrm{y}$ of age $\pm 3 \mathrm{mo}$. Of the seven regions engaged, threeLund, Stockholm, and Umeå-conducted vascular assessments in addition to neurodevelopmental testing. Of the 494 survivors in the EXPRESS cohort, 250 (51\%) were from these three regions.

Exclusion criteria were congenital cardiovascular $(n=12)$ or pulmonary malformations $(n=0)$, ongoing chronic cardiovascular conditions $(n=2 ; 1$ bilateral pulmonary artery branch stenosis and 1 left ventricular outflow obstruction) or ongoing chronic lung disease besides asthma at assessment age (i.e., cystic fibrosis, chronic bronchiectasis, atelectasis, lobar emphysema, chronic restrictive lung disease; $n=0)$. Twenty-seven children were lost because they could not be assessed within the age limits. Forty families declined participation and seven had emigrated or had no address, leaving 176 children born extremely preterm (EXP) that were formally assessed (70\%) (Figure 1). Drop-out analysis did not disclose any significant difference in mean gestational age at birth (participants $=25.4$ vs. nonparticipants $=$ $25.3 \mathrm{wk}, P=0.13$ ), mean birth weight ( $785 \mathrm{vs.} 769 \mathrm{~g}, P=0.15$ ) or sex distribution ( 45 vs. $50 \%$ girls, $P=0.39$ ) between those participating in the study and those lost to follow-up.

Using the Swedish Medical Birth Register held at the National Board of Health and Welfare, each child born preterm was matched to a healthy control child born at term (CTRL) and with the same sex, date of birth, hospital, residency and mothers' country of birth. A pool of 10 controls for each preterm participant was randomly selected from the Swedish Medical Birth Register. Invitations were sent until one control child for each preterm child accepted to participate. If all invited CTRL declined and the list of eligible children was depleted, they were listed as missing $(n=4)$ (Figure 1).

All parents and children invited to participate received oral and written information, and the parents/legal guardians signed informed consent. Study approval was obtained from the Regional Ethics Review Board in Stockholm (no. 2010/520-31/2 and amendment no.2011/376-32). Follow-up ended in January 2014.

\section{Clinical and Vascular Assessments}

Standardized operational procedures were used for all assessments and all examiners were blinded to group belonging. Families were scheduled to attend in the morning. Participants medical history,
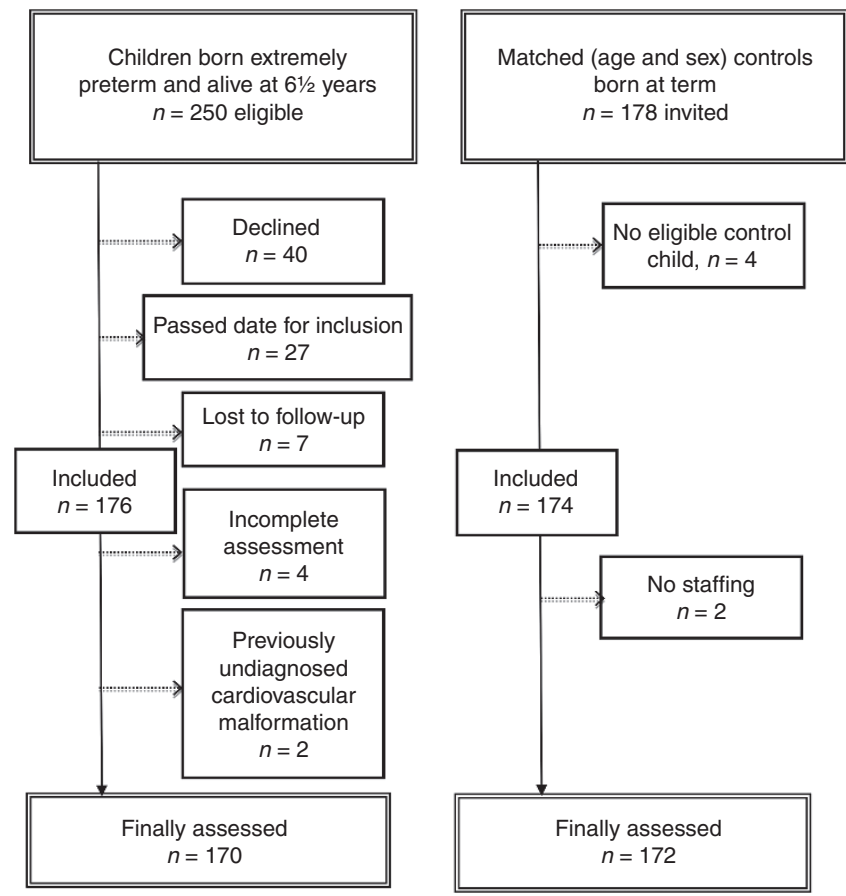

Figure 1. Flow chart of study participants. maternal smoking and parents' medical history were obtained using a questionnaire.

At arrival, height and weight, as well as head- and waist circumferences were measured. BMI was calculated as weight $/$ height $^{2}$ and body surface area (BSA) was calculated according to Haycock (27).

Estimations of arterial stiffness included measurements of blood pressure. After at least $15 \mathrm{~min}$ of calm acclimatization to the investigation room and while the children were seated in a chair or their parents lap, a validated oscillometric device, Omron HEM 907 (Omron Healthcare, Kyoto, Japan) was used to measure systolic (SBP) and diastolic (DBP) blood pressures in the right arm with an appropriate cuff size. Blood pressure was possible to measure once $(n=6)$, twice $(n=$ $10)$, or three times $(n=328)$ with at least 2 min between consecutive measurements, and mean values were calculated.

\section{Measurement of Coronary, Carotid, and Aortic Diameters}

For diameter measurements, two-dimensional (2D) ultrasonography scans were performed. A multi-frequency 8-15 $\mathrm{MHz}$ linear array transducer (Acuson, Sequoia 512, Mountain View, CA) and a multifrequency 8-3 MHz sector transducer (Acuson, SC2000, Mountain View, CA) were used in Stockholm. In Umeå and Lund regional hospitals, a multi-frequency $15-7 \mathrm{MHz}$ linear array transducer (Philips L15-7io) and a multi-frequency $8-5 \mathrm{MHz}$ sector transducer (Philips iE33, Philips Health Care, The Netherlands) were used. Temporal resolution was set to 60-90 frames per second.

All participants were investigated by the same experienced ultrasound examiner at each center (OB, LAM, and $\mathrm{MH})$. With the child resting in the supine position, left and right coronary arteries (CA) were visualized and recorded using the parasternal short axis view. The coronary arteries inner diameter were measured at maximal expansion (28), right coronary artery and left main coronary artery proximal to aortic root, left anterior descending artery proximal to left main coronary artery. The common carotid arteries (CCA) were recorded $10 \mathrm{~mm}$ proximal to the carotid bulb (transverse and longitudinal planes). The aortic valve annulus was recorded between the hinge points of the aortic valve (parasternal long-axis view) and the abdominal aorta (AA) was studied $10 \mathrm{~mm}$ above the mesenteric and celiac arteries (subcostal long-axis view). All measuring sites were recorded using standardized protocols and digitally stored with 1-3 cine-loops of three R-R intervals with a three-led ECG for later analysis (29).

All image analyses were performed off-line and blinded to group belonging. One operator analyzed the images recorded in UmeàStockholm (LAM) and another in Lund (OB). Common carotids and AA inner diameters $(\mathrm{mm})$ were measured in end-diastole and peak systole, and aortic valve annulus diameter at end-systole (identified by ECG) as cross-sectional point measurements.

\section{Measurement of Carotid Intima-Media Thickness}

Left and right carotid intima media thicknesses (cIMT) were measured in end-diastole at the far wall in a region of interest $10 \mathrm{~mm}$ long, starting at the proximal end of the carotid bulb. A semiautomatic system (Arterial Health Package, Siemens, Acuson, CA) was used and a mean value from three consecutive measurements was calculated.

\section{Measurement of Carotid and Aortic Stiffness}

Arterial stiffness was estimated using blood pressure data and the magnitude of the pulsatile diameter changes. CCA and AA strain were calculated as the relative pulsatile diameter change $(\Delta D)$ according to the formula: Peak systolic diameter - end-diastolic diameter $(\Delta \mathrm{D}) /$ end-diastolic diameter ${ }^{\star} 100$

The stiffness index $(\beta)$ for CCA and AA was calculated using the formula (17): $\ln (\mathrm{SBP} / \mathrm{DBP}) /$ strain.

\section{Statistical Analyses}

Results are reported as means and SD or numbers (proportions and percentages). The distributions of vascular outcomes were found to be normal according to Shapiro-Wilk test. All vascular outcomes were not possible to measure in all participants and the success rate varied between 79 and $95 \%$. Numbers of successful measurements are given in each respective Table.

For group comparisons, Student's $t$-test or Chi-squared test was used. Arterial diameters are presented as crude and adjusted values 
using multiple linear regression analyses including group (EXP/ CTRL), BSA, and site/investigator as independent variables. Before testing for group differences between EXP and CTRL, we investigated if family history of CVD (defined as a history of myocardial infarction, stroke, or hypertension in first degree relatives to mother or father), maternal university education (defined as more than $12 \mathrm{y}$ of total length of formal education) and maternal smoking in pregnancy were associated with the different vascular outcomes. After testing for group differences between EXP and CTRL, we investigated if gestational age (22-24 or $25-26 \mathrm{wk}$ ), small for gestational age at birth (SGA at birth, defined as birth weight $2 \mathrm{SD}$ or more below the mean for a Swedish reference for normal fetal growth (26)), as well as SGA at $36 \mathrm{wk}$ (defined as a weight at $36 \mathrm{wk}$ of postmenstrual age of $2 \mathrm{SD}$ or more below the mean for a Swedish reference (30)) were associated to the vascular outcomes. A $P$ value $<0.05$ was considered as statistically significant.

\section{RESULTS}

In total, 348 children were assessed: 176 EXP and 172 CTRL. Both groups had similar rates of a family history of CVD. The proportion of university educated mothers was lower and smoking in pregnancy was more common in EXP than in CTRL. There was no group difference in participants' chronological age at examination, but weight, height, BMI, and BSA were lower in EXP than in CTRL. Heart rate was higher in EXP than in CTRL, whereas SBP and DBP did not differ between the two groups (Table 1 ).

\section{Coronary, Carotid, and Aortic Diameters}

A positive family history of CVD in first-degree relatives to the parents $(256 / 348=74 \%)$, maternal university education $(186 / 348=53 \%)$ or maternal smoking in pregnancy $(11 / 348$ $=3.2 \%$ ) showed no association with arterial dimensions at 6.5 y of age, except for a $3.0 \%$ smaller right CCA $(P=0.02)$ in children with a family history of CVD and $3.9 \%$ wider aortic annulus valve $(P<0.001)$ in children to mothers with university education (data not shown).

Unadjusted arterial diameters were significantly smaller in EXP than in CTRL $(P<0.005$ for all comparisons). The coronary arteries were $6.7-10.5 \%$ narrower, with the largest difference in the left anterior descending artery. The left carotid artery was 4.3\% narrower and the right carotid artery 6.3\% narrower in EXP than in CTRL. The aortic valve annulus was $8.6 \%$ and the abdominal aorta was on average 9.3\% narrower in EXP than in CTRL. However, after adjusting arterial diameters for current body surface area and site, these group differences in arterial dimensions diminished (left CA, right CCA, aorta) or disappeared (right CA, left anterior descending CA, left CCA) (Table 2).

In EXP, arterial dimensions adjusted for BSA and site were similar or slightly smaller (right and left anterior descending CA) in children born at 22-24wk of gestation than in 25-26 wk of gestation (Table 3). Arterial dimensions in EXPchildren did not differ in relation to being born SGA or AGA (Table 4) or in relation to being SGA or AGA 10 to $14 \mathrm{wk}$ after birth, i.e., at $36 \mathrm{wk}$ of postmenstrual age (Table 5).

\section{Carotid Intima Media Thickness}

The overall mean common carotid IMT (cIMT) was 0.38 $(\mathrm{SD}=0.04) \mathrm{mm}$. A family history of CVD $(256 / 348=74 \%)$ was
Table 1. Characteristics in 6.5-y-old children born extremely preterm (EXP) and in controls born at term (CTRL)

\begin{tabular}{|c|c|c|c|}
\hline & $\operatorname{EXP}(n=176)$ & $\operatorname{CTRL}(n=172)$ & $P$ value \\
\hline \multicolumn{4}{|l|}{ Maternal data } \\
\hline Age, years (mean and range) & $31.4(18-46)$ & $31.8(21-43)$ & 0.47 \\
\hline $\begin{array}{l}\text { Family history of } \\
\text { cardiovascular disease }\end{array}$ & $129(73 \%)$ & $127(74 \%)$ & 0.80 \\
\hline University education & $82(47 \%)$ & $104(61 \%)$ & 0.009 \\
\hline \multicolumn{4}{|l|}{ Pregnancy data } \\
\hline Maternal smoking & $9(5 \%)$ & $2(1 \%)$ & 0.03 \\
\hline Preeclampsia & $16(10 \%)$ & 0 & - \\
\hline Multiple fetuses & $29(17 \%)$ & 0 & - \\
\hline \multicolumn{4}{|l|}{ Neonatal data } \\
\hline Gestational age, weeks & $24.9(1.0)$ & $39.4(1.2)$ & - \\
\hline Range & $22-26$ & $37-41$ & - \\
\hline Males & $97(55 \%)$ & $99(58 \%)$ & 0.65 \\
\hline Birth weight, g & $787(165)$ & $3,591(461)$ & - \\
\hline Range & $348-1,161$ & $2,430-4,315$ & - \\
\hline SGA at birth & $27(16 \%)$ & 0 & - \\
\hline $\begin{array}{l}\text { SGA at } 36 \mathrm{wk} \text { of } \\
\text { postmenstrual age }\end{array}$ & $76 / 161^{\mathrm{a}}(47 \%)$ & - & - \\
\hline \multicolumn{4}{|l|}{ 6.5-y follow-up } \\
\hline Age, months & $80(2.1)$ & $80(2.3)$ & 0.22 \\
\hline Weight, kg & $20.6(3.6)$ & $24.2(4.1)$ & $<0.001$ \\
\hline Height, cm & $118(5.6)$ & $123(4.8)$ & $<0.001$ \\
\hline $\mathrm{BMI}, \mathrm{kg} / \mathrm{m}^{2}$ & $15.1(1.6)$ & $16.4(2.1)$ & $<0.001$ \\
\hline $\mathrm{BSA}, \mathrm{m}^{2}$ & $0.82(0.09)$ & $0.91(0.09)$ & $<0.001$ \\
\hline
\end{tabular}

\section{Heart rate and blood pressure}

$\begin{array}{lccc}\text { Heart rate, bpm } & 88(13) & 84(10) & 0.003 \\ \text { SBP, } \mathrm{mmHg} & 98(8) & 98(8) & 0.63 \\ \mathrm{DBP}, \mathrm{mmHg} & 57(6) & 56(7) & 0.21\end{array}$

Data are mean (SD) or numbers (\%) if not indicated otherwise.

aSome missing data.

BSA, body surface area; DBP, diastolic blood pressure; SBP, systolic blood pressure; SGA, small for gestational age.

associated with a thinner cIMT (right side $=-0.02 \mathrm{~mm}, P=$ 0.006 , and left side $=-0.02 \mathrm{~mm}, P=0.001$ ) compared with children without a family history of CVD. Neither maternal university education nor smoking in pregnancy was associated with cIMT in 6-y-old children.

The cIMT did not differ between EXP and CTRL, or between the left and right common carotid artery. The relative cIMT (IMT in relation to carotid inner diameter) was thicker in EXP than in CTRL (Table 6).

In EXP, cIMT (absolute or relative) did not differ between those born at weeks 22-24 and 25-26, between those born 


\section{Articles $\mid$ Mohlertetal.}

Table 2. Arterial inner diameters $(\mathrm{mm})$ in 6.5-y-old children born extremely preterm (EXP) and in controls born at term (CTRL)

\begin{tabular}{|c|c|c|c|c|c|c|}
\hline & EXP & CTRL & $\begin{array}{l}\text { Crude mean difference } \\
\qquad(95 \% \mathrm{Cl})\end{array}$ & $P$ value & $\begin{array}{l}\text { Adjusted }^{\mathrm{a}} \text { mean difference } \\
\qquad(95 \% \mathrm{Cl})\end{array}$ & $P$ value \\
\hline Coronary arteries $^{b}$ & $(n=149)$ & $(n=163)$ & & & & \\
\hline Left main & $3.0(0.7)$ & $3.2(0.6)$ & $-0.23(-0.37 ;-0.08)$ & 0.002 & $-0.14(-0.25 ;-0.03)$ & 0.02 \\
\hline Right & $2.4(0.4)$ & $2.6(0.4)$ & $-0.19(-0.28 ;-0.09)$ & $<0.001$ & $-0.08(-0.17 ; 0.02)$ & 0.12 \\
\hline Left anterior descending & $1.7(0.3)$ & $1.9(0.3)$ & $-0.13(-0.21 ;-0.04)$ & 0.004 & $-0.05(-0.15 ; 0.04)$ & 0.28 \\
\hline Right & $4.5(0.4)$ & $4.8(0.4)$ & $-0.28(-0.38 ;-0.18)$ & $<0.001$ & $-0.20(-0.31 ;-0.09)$ & $<0.001$ \\
\hline Aorta & $(n=151)$ & $(n=159)$ & & & & \\
\hline Aortic valve annulus & $13.9(1.1)$ & $15.2(1.2)$ & $-1.29(-1.54 ;-1.03)$ & $<0.001$ & $-0.87(-1.1 ;-0.64)$ & $<0.001$ \\
\hline Proximal abdominal & $7.3(0.8)$ & $8.1(0.9)$ & $-0.74(-0.94 ;-0.53)$ & $<0.001$ & $-0.45(-0.67 ;-0.23)$ & $<0.001$ \\
\hline
\end{tabular}

Values represent mean (SD) and mean difference (95\% confidence intervals).

arepresent mean difference adjusted for body surface area $\left(\mathrm{m}^{2}\right)$ and site. ${ }^{\mathrm{b}}$ Proximal innerdiameter.

Table 3. Arterial inner diameters $(\mathrm{mm})$ in 6.5-y-old children born extremely preterm stratified by gestational age

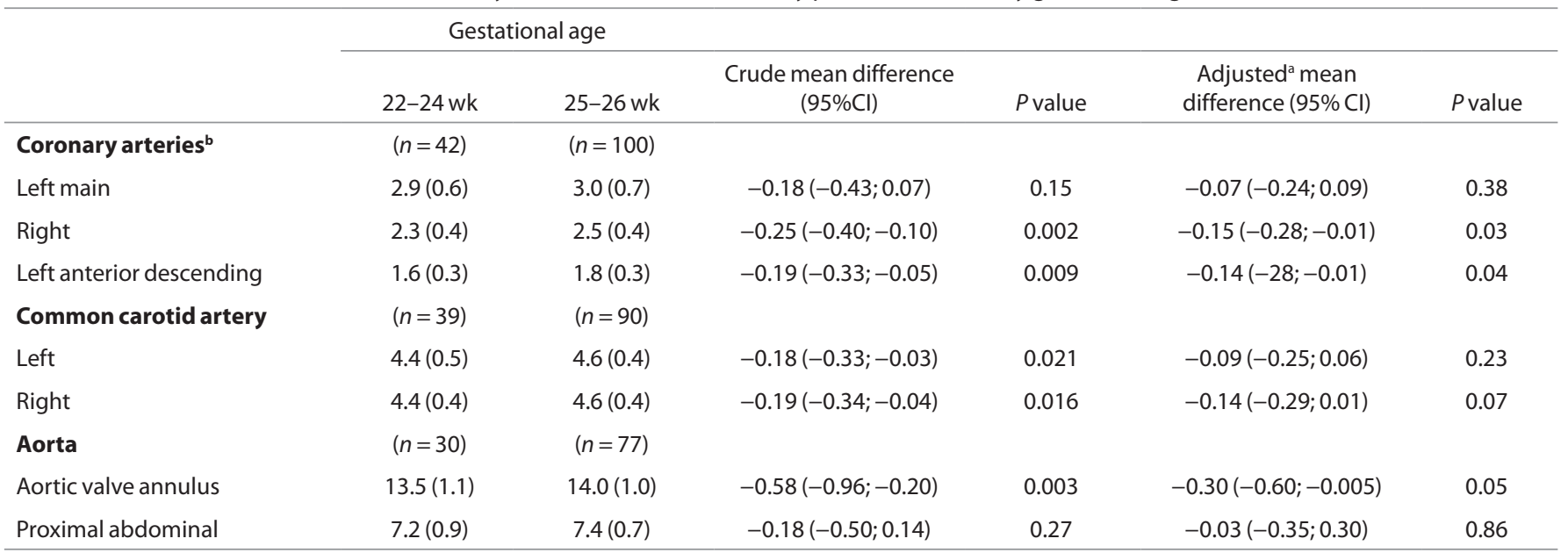

Values represent mean (SD) or mean difference ( $95 \%$ confidence interval).

a Mean difference (22-24 minus 25-26 wk) adjusted for body surface area $\left(\mathrm{m}^{2}\right)$ and site. ${ }^{\mathrm{b}}$ Proximal innerdiameter.

SGA and AGA, or between those SGA and AGA at $36 \mathrm{wk}$ of postmenstrual age.

\section{Carotid and Aortic Strain and Stiffness Index}

Carotid strain-i.e., the relative systolic to diastolic diameter change-and stiffness index at $6 \mathrm{y}$ of age were not associated with a family history of CVD, maternal university education, or smoking in pregnancy.

Aortic strain was $7.7 \%$ lower $(P=0.049)$ and aortic stiffness index $15 \%$ higher in children with a family history of CVD $(P=0.010)$, whereas maternal university education or smoking in pregnancy were not associated with aortic strain or stiffness index.

Carotid strain was approximately 5\% higher and carotid stiffness was on average 8.2\% lower in EXP than in CTRL. Strain and stiffness index of the abdominal aorta did not differ between the two groups (Table 7).

Left carotid stiffness index was 14\% lower in EXP born at 2224 wk compared with $25-26 \mathrm{wk}(P=0.009)$, but right carotid and aortic stiffness were not related to gestational age. Carotid or aortic stiffness indices did not differ between EXP-children born SGA or with appropriate birth weight. In EXP-children SGA at $36 \mathrm{wk}$ of postmenstrual age, left carotid stiffness index was $10 \%$ lower than in those AGA at $36 \mathrm{wk}$ of postmenstrual age $(P=0.014)$, whereas right carotid or aortic stiffness did not relate to SGA or AGA at $36 \mathrm{wk}$ of postmenstrual age (data not shown).

\section{DISCUSSION}

In this study of vascular outcomes in childhood survivors of preterm birth at $22-26 \mathrm{wk}$ of gestation, we found that the aorta, the coronary, and carotid arteries were $5-10 \%$ narrower than in age- and sex-matched controls born at term. However, children born extremely preterm were still at $6 \mathrm{y}$ of age smaller (on average $3.6 \mathrm{~kg}$ lighter and $5 \mathrm{~cm}$ shorter) than their peers born at term. After adjusting arterial diameters for current body surface area, the differences between the groups became smaller or disappeared. Carotid intima-media thickness was 
Table 4. Arterial inner diameters $(\mathrm{mm})$ in 6.5-y-old children born extremely preterm stratified by small (SGA) or appropriate for gestational age (AGA) at birth

\begin{tabular}{|c|c|c|c|c|c|c|}
\hline & SGA at birth & AGA at birth & $\begin{array}{c}\text { Crude mean } \\
\text { difference }(95 \% \mathrm{Cl})\end{array}$ & $P$ value & $\begin{array}{l}\text { Adjusted }^{\mathrm{a}} \text { mean } \\
\text { difference }(95 \% \mathrm{Cl})\end{array}$ & $P$ value \\
\hline Coronary arteries ${ }^{b}$ & $(n=20)$ & $(n=122)$ & & & & \\
\hline Left main & $2.7(0.8)$ & $3.0(0.6)$ & $-0.37(-0.69 ;-0.05)$ & 0.03 & $-0.03(-0.25 ; 0.19)$ & 0.79 \\
\hline Right & $2.3(0.6)$ & $2.5(0.4)$ & $-0.19(-0.39 ; 0.01)$ & 0.07 & $-0.008(-0.17 ; 0.19)$ & 0.93 \\
\hline Left anterior descending & $1.7(0.3)$ & $1.8(0.3)$ & $-0.08(-0.27 ; 0.13)$ & 0.46 & $-0.02(-0.22 ; 0.19)$ & 0.88 \\
\hline Right & $4.6(0.4)$ & $4.6(0.4)$ & $0.07(-0.14 ; 0.28)$ & 0.51 & $0.13(-0.07 ; 0.34)$ & 0.20 \\
\hline Aorta & $(n=22)$ & $(n=124)$ & & & & \\
\hline Aortic valve annulus & $13.5(1.1)$ & $13.9(1.1)$ & $-0.41(-0.90 ; 0.08)$ & 0.10 & $-0.09(-0.47 ; 0.28)$ & 0.62 \\
\hline Proximal abdominal & $7.4(0.6)$ & $7.3(0.8)$ & $0.05(-0.39 ; 0.50)$ & 0.82 & $0.18(-0.26 ; 0.62)$ & 0.41 \\
\hline
\end{tabular}

Values represent mean (SD) and mean difference ( $95 \%$ confidence interval).

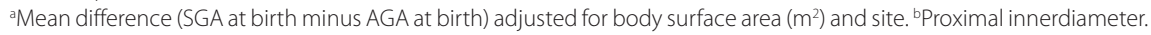

Table 5. Arterial inner diameters ( $\mathrm{mm}$ ) in 6.5-y-old children born extremely preterm and stratified by small (SGA) or appropriate for gestational age (AGA) at $36 \mathrm{wk}$ of postmenstrual age

\begin{tabular}{|c|c|c|c|c|c|c|}
\hline & SGA at 36 wk & AGA at 36 wk & $\begin{array}{c}\text { Crude mean } \\
\text { difference }(95 \% \mathrm{Cl})\end{array}$ & $P$ value & $\begin{array}{c}\text { Adjusted }{ }^{\mathrm{a}} \text { mean } \\
\text { difference }(95 \% \mathrm{Cl})\end{array}$ & $P$ value \\
\hline Coronary arteries $^{b}$ & $(n=63)$ & $(n=71)$ & & & & \\
\hline Right & $2.4(0.5)$ & $2.5(0.4)$ & $-0.12(-0.27 ; 0.03)$ & 0.12 & $-0.08(-0.21 ; 0.05)$ & 0.23 \\
\hline Left anterior descending & $1.8(0.3)$ & $1.7(0.3)$ & $0.06(-0.07 ; 0.19)$ & 0.35 & $0.11(-0.02 ; 0.24)$ & 0.09 \\
\hline Right & $4.5(0.4)$ & $4.6(0.4)$ & $-0.09(-0.24 ; 0.06)$ & 0.22 & $-0.02(-0.16 ; 0.12)$ & 0.78 \\
\hline Aorta & $(n=66)$ & $(n=72)$ & & & & \\
\hline Aortic valve annulus & $13.8(1.0)$ & $13.9(1.1)$ & $-0.15(-0.51 ; 0.22)$ & 0.42 & $-0.07(-0.35 ; 0.20)$ & 0.59 \\
\hline Proximal abdominal & $7.2(0.7)$ & $7.4(0.8)$ & $-0.13(-0.43 ; 0.18)$ & 0.41 & $0.04(-0.27 ; 0.34)$ & 0.80 \\
\hline
\end{tabular}

Values represent mean (SD) and mean difference ( $95 \%$ confidence interval).

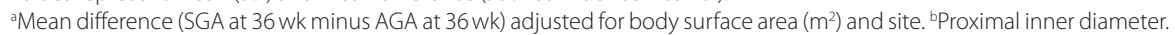

Table 6. IMT of the CCA in 6.5-y-old children born extremely preterm (EXP) and controls at term (CTRL)

\begin{tabular}{lcccc}
\hline & EXP & CTRL & $\begin{array}{c}\text { Mean difference } \\
(95 \% \mathrm{Cl})\end{array}$ & $P$ value \\
\hline Absolute IMT, $\mathbf{m m}$ & $(n=114)$ & $(n=121)$ & & \\
Left CCA & $0.38(0.04)$ & $0.38(0.04)$ & $0.01(-0.01 ; 0.02)$ & 0.30 \\
Right CCA & $0.38(0.04)$ & $0.37(0.04)$ & $0.01(-0.002 ; 0.02)$ & 0.12 \\
Relative IMT,\% & $(n=110)$ & $(n=118)$ & & \\
Left CCA & $16.7(2.3)$ & $16.1(2.1)$ & $0.60(0.02 ; 1.2)$ & 0.042 \\
Right CCA & $16.9(2.3)$ & $15.6(1.9)$ & $1.3(0.8 ; 1.9)$ & $<0.001$ \\
\hline
\end{tabular}

Absolute IMT-values presented in millimetres and relative IMT as percentages. Values represent mean (SD) and mean difference (95\% confidence interval).

Relative IMT $=(($ IMT CCA*2)/CCA inner diameter $) * 100$.

CCA, common carotid arteries; IMT, Intima media thickness.

similar in the two groups and the carotid (but not aortic) stiffness was lower in children born extremely preterm than in those born at term. These results could not be explained by group differences in maternal education or smoking during pregnancy-both proxies for socioeconomic status-or by a family history of CVD.

In previous studies, we reported decelerated arterial growth after preterm birth (12) and 16-19\% smaller aortic cross-sectional luminal area (corresponding to $4-5 \%$ shorter arterial diameter) in adolescents born very preterm, also after adjusting for body surface area (13). Persistent aortic narrowing is in line with our present findings. Another study concluded that after adjustment for BSA, diameters of the abdominal aorta, carotid, and popliteal arteries were not significantly different between 7-y-old children born preterm or at term (31). However, given a sample size of 32 children in each group (31) a similar effect-size as in our study could not be detected. In addition, differences in arterial diameters might become more apparent once final catch-up of somatic growth has occurred, i.e., in adolescence and in adulthood. Different arteries may also exhibit different growth trajectories: although we 


\section{Articles $\mid$ Mohlertetal.}

Table 7. Dynamic properties of the common carotid arteries and the proximal abdominal aorta in 6.5-y-old children born extremely preterm (EXP) and controls born at term (CTRL)

\begin{tabular}{|c|c|c|c|c|}
\hline & EXP & CTRL & $\begin{array}{l}\text { Mean difference } \\
\quad(95 \% \mathrm{Cl})\end{array}$ & $P$ value \\
\hline \multicolumn{5}{|c|}{ Common carotid artery } \\
\hline Left & $(n=135)$ & $(n=149)$ & & \\
\hline$\Delta \mathrm{D}, \mathrm{mm}$ & $0.09(0.02)$ & $0.09(0.02)$ & $0.0(-0.005 ; 0.004)$ & 0.68 \\
\hline Strain, \% & $20(4.6)$ & $19(4.3)$ & $1.0(0.03 ; 2.1)$ & 0.045 \\
\hline Stiffness index & $2.8(0.7)$ & $3.1(0.8)$ & $-0.3(-0.5 ;-0.1)$ & 0.002 \\
\hline Right & $(n=118)$ & $(n=124)$ & & \\
\hline$\Delta \mathrm{D}, \mathrm{mm}$ & $0.09(0.02)$ & $0.09(0.02)$ & $0.0(-0.04 ; 0.04)$ & 1.00 \\
\hline Strain, \% & $21(3.8)$ & $20(3.8)$ & $1.1(0.02 ; 2.1)$ & 0.024 \\
\hline Stiffness index & $2.8(0.8)$ & $3.0(0.8)$ & $-0.3(-0.5 ;-0.1)$ & 0.007 \\
\hline Abdominal aorta & $(n=112)$ & $(n=121)$ & & \\
\hline$\Delta \mathrm{D}, \mathrm{mm}$ & $0.21(0.05)$ & $0.23(0.05)$ & $-0.02(-0.03 ;-0.01)$ & 0.007 \\
\hline Strain, \% & $29(7.9)$ & $28(7.5)$ & $0.3(-1.7 ; 2.3)$ & 0.80 \\
\hline Stiffness index & $2.1(0.8)$ & $2.1(0.7)$ & $0.04(-0.2 ; 0.2)$ & 0.67 \\
\hline
\end{tabular}

Values represent mean (SD) and mean difference ( $95 \%$ confidence interval).

previously demonstrated that both the aorta and the carotid arteries suffered from grow failure in the first 6 mo after very preterm birth (12) the aorta appears to be more sensitive to long-lasting growth retardation than the carotid arteries $(14,20,32)$. These interpretations are supported by recent data demonstrating aortic narrowing in young adults born very preterm, but similar carotid and brachial artery size as in adults born at term (33).

The study of coronary arteries in children born extremely preterm is an unexplored field. Reassuringly, our results of coronary diameters correspond to previously reported normal ranges for healthy children (34). And after adjusting coronary diameters to body surface area, the group differences diminished $(4.3 \%)$ or disappeared below our detection limit $(<4 \%)$. However, the unadjusted findings of $6.7-10.5 \%$ narrower coronaries-corresponding to an 11 to $21 \%$ smaller luminal area-in children born EXP may have implications for the future CVD-risk in adulthood: a small coronary inner diameter has been identified as an independent predictor of atherosclerotic lesions (35). We suggest that the growth and development of the coronary arteries in EXP, as well as the myocardial flow reserve, should be assessed until adult age. Studies on possible perinatal mediators of coronary artery narrowing after preterm birth, e.g., patent ductus arteriosus and its treatment (36), and studies on the correlation between coronary artery diameter and left ventricular mass are also warranted (37).

Maternal smoking during pregnancy has previously been associated with lasting aortic narrowing (19). We could not confirm such an association in this study, possibly related to small numbers ( $n=11$ out of 348 ) of smoking mothers and limitations in power.
Fetal growth restriction is a perinatal risk factor associated with growth failure of the arterial tree in childhood $(37,38)$. We found no association between prenatal growth failure and arterial size at $6 \mathrm{y}$ of age. As children born SGA in our study had been exposed to intrauterine growth restriction for a limited period of time (due to induced delivery at low gestational age), the effect of fetal growth restriction may be relatively smaller than in other studies. In addition, the small number of children born SGA in this study $(n=27)$ contribute to limitations in power.

Postnatal growth failure in the neonatal period was not associated with smaller arteries at $6 y$ of age. We find this intriguing as fetal growth failure during the same developmental period, i.e., the third trimester, has been associated with permanent narrowing of the aorta and popliteal arteries (38). In addition, as opposed to children born thin at term because of intrauterine growth restriction (39), we did not find any signs of increased carotid stiffness in EXP children. On the contrary, their carotid arteries were more elastic than those of children born at term. The absence of an association between preterm birth and accelerated arterial stiffening is in line with some $(14,17)$ but not all $(21,23)$ previous studies. Comparisons are complicated by different methods as well as different age groups and vascular segments.

Based on histological data (40), we think carotid intima media thickness can be an appropriate measure of subclini$\mathrm{cal}$ arteriosclerosis also in small children. The carotid intima media thickness reported herein corresponds to previously reference data in healthy 6-y-old children (29). Accelerated carotid intima media thickening did not occur in EXP. Similar observations have been made in adolescents (19) and young adults born preterm (17). Considering normal or even enhanced carotid elasticity as well as normal endothelial function (14-17), there is so far no obvious vascular clue explaining why there is an inverse association between low gestational age at birth and increased adult mortality from stroke (6-8). Either the increased carotid pulsatility found in children born preterm contribute to compromise carotid function later in early middle age, or the underlying mechanisms may instead be related to increased blood pressure and development of hypertension after preterm birth $(2,3)$.

Strengths of this study include the population-based and prospective design. Recruitment of a large cohort of survivors born at 22-26 wk of gestation having a thorough vascular follow-up at $6 y$ of age is also one of the important new contributions of this study as prior studies of children born preterm mostly included those born more mature and after longer gestations. The control group was carefully chosen to avoid selection bias. Blinding of those performing the measurements and analyses minimized observer bias and drop-out analysis did not indicate any response bias.

Limitations include that causality cannot be proven for any association between preterm birth and later vascular outcome, and genetic or other sources of confounding cannot be excluded. Although the total number of participants allowed for detection of even small effects/group differences (down to 
$0.3 \mathrm{SD})$ with sufficient power (0.80), smaller numbers in some of the subgroup analyses may limit conclusions about statistically insignificant differences. We studied some but not all systemic arteries, and the arteries of the pulmonary circulation were not included. Blood sampling for lipid profiling, inflammatory status, or other biomarkers of vascular aging was not performed. Arterial stiffness was studied in segments of the common carotid artery and the abdominal aorta, but we did not evaluate pulse wave velocity over the entire aorta. Finally, arterial blood flow and vascular resistance were not assessed.

The most important clinical implication of our findings is that before $6 \mathrm{y}$ of age, there seems to be no need for routine investigation of the systemic arteries in children born extremely preterm. If preterm narrowing of the arterial tree in the future studies should be linked to increased risk for cardiovascular morbidity and mortality at later age, we think that the roots and opportunities for interventions should primarily be sought in the neonatal period (12).

In the clinical situation, indexing the arterial diameter by dividing it with BSA may be an accepted way to account for variations in body size. In our study, the average BSA-indexed arterial diameters were found to be similar or even wider in EXP than in CTRL (data not shown). This demonstrates that in situations of marked variations in BSA such as in children born extremely preterm, indexed arterial diameters may be heavily dependent on the denominator (BSA) and thereby may become difficult to interpret.

In summary, healthy 6-y-old children surviving after extremely preterm birth have a smaller or similar sized arterial tree, similar intima media thickness, and similar or even decreased arterial stiffness compared with age- and sex-matched control children born at term. For a better understanding of the link between preterm birth and cardiovascular disease in adult life, further studies are needed. Such research agenda include longer-term follow-up of the cardiovascular system in older children and adults born extremely preterm, studies of smaller arteries and the microcirculation (16), links to current cardiometabolic status as well as to perinatal living conditions.

\section{ACKNOWLEDGMENTS}

Assistance with data collection by Lena Swartling Schlinzig, Karolinska University Hospital, Ann-Cathrine Berg, Lund University and Barbro Fossmo, Umeå University is gratefully acknowledged. The authors also want to acknowledge the following members of the EXPRESS study group for contributing to the perinatal data collection: Mats Blennow, Karin Källén, Karel Marsal, and Fredrik Serenius.

\section{STATEMENT OF FINANCIAL SUPPORT}

This study was supported by the Swedish Heart-Lung Foundation, the Swedish Order of Freemasons' Foundation for Children's Welfare, Stockholm Odd Fellow foundation and by a regional agreement on medical training and clinical research (ALF) between Stockholm County Council and Karolinska Institutet in Stockholm, and between Lund University and Skåne University Hospital, Sweden.

Disclosures: None.

\section{REFERENCES}

1. Fellman V, Hellström-Westas L, Norman M, et al.; EXPRESS Group. Oneyear survival of extremely preterm infants after active perinatal care in Sweden. JAMA 2009;301:2225-33.
2. Johansson S, Iliadou A, Bergvall N, Tuvemo T, Norman M, Cnattingius S. Risk of high blood pressure among young men increases with the degree of immaturity at birth. Circulation 2005;112:3430-6.

3. de Jong F, Monuteaux MC, van Elburg RM, Gillman MW, Belfort MB. Systematic review and meta-analysis of preterm birth and later systolic blood pressure. Hypertension 2012;59:226-34.

4. Hovi P, Andersson S, Eriksson JG, et al. Glucose regulation in young adults with very low birth weight. N Engl J Med 2007;356:2053-63.

5. Li S, Zhang M, Tian H, Liu Z, Yin X, Xi B. Preterm birth and risk of type 1 and type 2 diabetes: systematic review and meta-analysis. Obes Rev 2014;15:804-11.

6. Koupil I, Leon DA, Lithell HO. Length of gestation is associated with mortality from cerebrovascular disease. J Epidemiol Community Health 2005;59:473-4.

7. Lawlor DA, Ronalds G, Clark H, Smith GD, Leon DA. Birth weight is inversely associated with incident coronary heart disease and stroke among individuals born in the 1950s: findings from the Aberdeen Children of the 1950s prospective cohort study. Circulation 2005;112:1414-8.

8. Ueda P, Cnattingius S, Stephansson O, Ingelsson E, Ludvigsson JF, Bonamy AK. Cerebrovascular and ischemic heart disease in young adults born preterm: a population-based Swedish cohort study. Eur J Epidemiol 2014;29:253-60.

9. Lewandowski AJ, Augustine D, Lamata P, et al. Preterm heart in adult life: cardiovascular magnetic resonance reveals distinct differences in left ventricular mass, geometry, and function. Circulation 2013;127:197-206.

10. Crump C, Sundquist K, Sundquist J, Winkleby MA. Gestational age at birth and mortality in young adulthood. JAMA 2011;306:1233-40.

11. Hellstrom A, Perruzzi C, Ju M, et al. Low IGF-I suppresses VEGF-survival signaling in retinal endothelial cells: direct correlation with clinical retinopathy of prematurity. Proc Natl Acad Sci USA 2001;98:5804-8.

12. Schubert U, Müller M, Edstedt Bonamy AK, Abdul-Khaliq H, Norman M. Aortic growth arrest after preterm birth: a lasting structural change of the vascular tree. J Dev Orig Health Dis 2011;2:218-25.

13. Edstedt Bonamy AK, Bengtsson J, Nagy Z, De Keyzer H, Norman M. Preterm birth and maternal smoking in pregnancy are strong risk factors for aortic narrowing in adolescence. Acta Paediatr 2008;97:1080-5.

14. Bonamy AK, Bendito A, Martin H, Andolf E, Sedin G, Norman M. Preterm birth contributes to increased vascular resistance and higher blood pressure in adolescent girls. Pediatr Res 2005;58:845-9.

15. Singhal A, Kattenhorn M, Cole TJ, Deanfield J, Lucas A. Preterm birth, vascular function, and risk factors for atherosclerosis. Lancet 2001;358: 1159-60.

16. Bonamy AK, Martin H, Jörneskog G, Norman M. Lower skin capillary density, normal endothelial function and higher blood pressure in children born preterm. J Intern Med 2007;262:635-42.

17. Hovi P, Turanlahti M, Strang-Karlsson S, et al. Intima-media thickness and flow-mediated dilatation in the Helsinki study of very low birth weight adults. Pediatrics 2011;127:e304-11.

18. Skilton MR, Viikari JS, Juonala M, et al. Fetal growth and preterm birth influence cardiovascular risk factors and arterial health in young adults: the Cardiovascular Risk in Young Finns Study. Arterioscler Thromb Vasc Biol 2011;31:2975-81.

19. Finken MJ, Inderson A, Van Montfoort N, et al.; Dutch POPS-19 Collaborative Study Group. Lipid profile and carotid intima-media thickness in a prospective cohort of very preterm subjects at age 19 years: effects of early growth and current body composition. Pediatr Res 2006;59(4 Pt 1): 604-9.

20. Bonamy AK, Andolf E, Martin H, Norman M. Preterm birth and carotid diameter and stiffness in childhood. Acta Paediatr 2008;97:434-7.

21. Cheung YF, Wong KY, Lam BC, Tsoi NS. Relation of arterial stiffness with gestational age and birth weight. Arch Dis Child 2004;89:217-21.

22. Lazdam M, de la Horra A, Pitcher A, et al. Elevated blood pressure in offspring born premature to hypertensive pregnancy: is endothelial dysfunction the underlying vascular mechanism? Hypertension 2010;56:159-65.

23. Oren A, Vos LE, Bos WJ, et al. Gestational age and birth weight in relation to aortic stiffness in healthy young adults: two separate mechanisms? Am J Hypertens 2003;16:76-9. 


\section{Articles | Mohlkertetal.}

24. Rossi P, Tauzin L, Marchand E, Simeoni U, Francès Y. [Arterial blood pressure and arterial stiffness in adolescents are related to gestational age]. Arch Mal Coeur Vaiss 2006;99:748-51.

25. EXPRESS Group. Incidence of and risk factors for neonatal morbidity after active perinatal care: extremely preterm infants study in Sweden (EXPRESS). Acta Paediatr 2010;99:978-92.

26. Serenius F, Källén K, Blennow M, et al.; EXPRESS Group. Neurodevelopmental outcome in extremely preterm infants at 2.5 years after active perinatal care in Sweden. JAMA 2013;309:1810-20.

27. Haycock GB, Schwartz GJ, Wisotsky DH. Geometric method for measuring body surface area: a height-weight formula validated in infants, children, and adults. J Pediatr 1978;93:62-6.

28. Lopez L, Colan SD, Frommelt PC, et al. Recommendations for quantification methods during the performance of a pediatric echocardiogram: a report from the Pediatric Measurements Writing Group of the American Society of Echocardiography Pediatric and Congenital Heart Disease Council. J Am Soc Echocardiogr 2010;23:465-95; quiz 576-7.

29. Doyon A, Kracht D, Bayazit AK, et al.; 4C Study Consortium. Carotid artery intima-media thickness and distensibility in children and adolescents: reference values and role of body dimensions. Hypertension 2013;62:550-6.

30. Marsál K, Persson PH, Larsen T, Lilja H, Selbing A, Sultan B. Intrauterine growth curves based on ultrasonically estimated foetal weights. Acta Paediatr 1996;85:843-8.

31. Morsing E, Liuba P, Fellman V, Maršál K, Brodszki J. Cardiovascular function in children born very preterm after intrauterine growth restriction with severely abnormal umbilical artery blood flow. Eur J Prev Cardiol 2014;21:1257-66.

32. Länne T, Hansen F, Mangell P, Sonesson B. Differences in mechanical properties of the common carotid artery and abdominal aorta in healthy males. J Vasc Surg 1994;20:218-25.

33. Boardman H, Birse K, Davis EF, et al. Comprehensive multi-modality assessment of regional and global arterial structure and function in adults born preterm. Hypertens Res 2016;39:39-45.

34. Oberhoffer R, Lang D, Feilen K. The diameter of coronary arteries in infants and children without heart disease. Eur J Pediatr 1989;148:389-92.

35. Nwasokwa ON, Weiss M, Gladstone C, Bodenheimer MM. Effect of coronary artery size on the prevalence of atherosclerosis. Am J Cardiol 1996;78:741-6.

36. Sehgal A, Ramsden CA, McNamara PJ. Indomethacin impairs coronary perfusion in infants with hemodynamically significant ductus arteriosus. Neonatology 2012;101:20-7.

37. Jiang B, Godfrey KM, Martyn CN, Gale CR. Birth weight and cardiac structure in children. Pediatrics 2006;117:e257-61.

38. Brodszki J, Länne T, Marsál K, Ley D. Impaired vascular growth in late adolescence after intrauterine growth restriction. Circulation 2005;111: 2623-8.

39. Martin H, Hu J, Gennser G, Norman M. Impaired endothelial function and increased carotid stiffness in 9-year-old children with low birthweight. Circulation 2000;102:2739-44.

40. Meyer WW, Lind J. Calcifications of the carotid siphon-a common finding in infancy and childhood. Arch Dis Child 1972;47:355-63. 